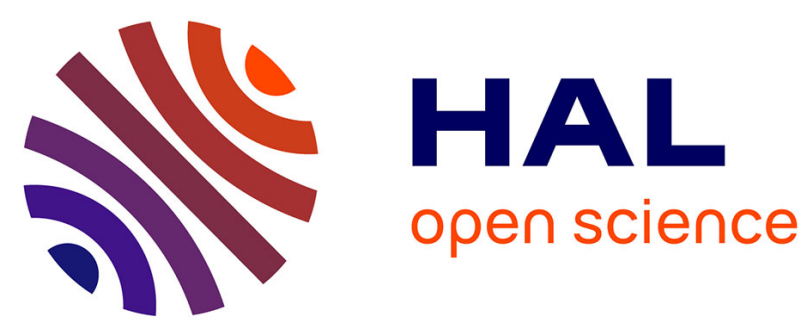

\title{
Electron Transfer at Platinum and Palladium Interfaces in Super-Dry Electrolytes. Generation of Iono-Metallic Layers. A Mini-Review
}

Jacques Simonet

\section{- To cite this version:}

Jacques Simonet. Electron Transfer at Platinum and Palladium Interfaces in Super-Dry Electrolytes. Generation of Iono-Metallic Layers. A Mini-Review. Electrochemistry Communications, 2015, 53, pp.15-19. 10.1016/j.elecom.2015.01.018 . hal-01114387

HAL Id: hal-01114387

https://hal-univ-rennes1.archives-ouvertes.fr/hal-01114387

Submitted on 28 Oct 2015

HAL is a multi-disciplinary open access archive for the deposit and dissemination of scientific research documents, whether they are published or not. The documents may come from teaching and research institutions in France or abroad, or from public or private research centers.
L'archive ouverte pluridisciplinaire $\mathbf{H A L}$, est destinée au dépôt et à la diffusion de documents scientifiques de niveau recherche, publiés ou non, émanant des établissements d'enseignement et de recherche français ou étrangers, des laboratoires publics ou privés. 


\title{
Electron Transfer at Platinum and Palladium Interfaces in Super-Dry Electrolytes. Generation of Iono-Metallic Layers.
}

\section{A Mini-Review.}

\author{
Jacques Simonet*
}

Equipe Masce, UMR 6226, Université de Rennes, 35830 Rennes Cedex, France.

\begin{abstract}
Metallic electrodes (gold, platinum) have been considered for long as inert and quasiideal electrodes both within the anodic and cathodic ranges. Here are gathers some striking evidences of the reactivity of platinum (and accessorily that of palladium) in aprotic polar solvents (water present $<200 \mathrm{ppm}$ ) for leading, by cathodic reaction with present electrolytes, to a large panel of iono-metallic layer. These modified metals layers may present many interesting behaviours: reductions via electron transfer, insertion by exchange of charged organic species inside the metallic matrix, catalysis, energy storage, etc... The highly foreseeable interest of those new materials and interfaces is briefly underlined in this mini-review.
\end{abstract}

Key words: Platinum cathodes; Palladium; Corrosion; Iono-metallic layers; Modified electrodes.

*Author: jacques.simonet@univ-rennes1.fr , Tel.: +33(0)223236292.

\section{Introduction}

For most of electrochemists connected with organic and inorganic electrochemistry (whatever the solvent and the salts), the incessant research of the perfect working electrode in matter of stability and efficiency, remains an recurrent question...Within the cathodic range, platinum as well as glassy carbon are seen as the most used electrode materials. They are believed as convenient and stable materials under cathodic polarization at least with $\mathrm{E}>-2 \mathrm{~V}$ vs. $\mathrm{Ag} / \mathrm{AgCl}$ system. Beyond, glassy carbon was found to trigger charge phenomena owing to the presence of imbedded graphite nanoparticles. Platinum is ineffective due to its too low hydrogen overvoltage when reaching moderately reducing potentials.

The present contribution aims to summarize the highly unexpected behaviour of platinum (together with that of palladium) when super-dry media are used especially for eliminating the inconvenience of those metals and getting a wider potential window at $\mathrm{E}<-1.8 \mathrm{~V}$. As a matter of fact, within such a potential range using superdry organic polar solvents in the contact of activated neutral alumina, the cathodic limit does not correspond anymore to hydrogen evolution, but the reduction of the 
metal itself to lead by reaction with the present electrolyte to a iono-metallic layer that covers the metal surface.

Such reaction strongly recalls the cathodic behaviour of mercury with electrogenerated alkali metals (sodium, potassium) to form readily amalgams at potentials $<-1.8 \mathrm{~V}$ vs. SCE. Ammonium salts (cation: tetraalkyl ammonium) may be formed at much more negative potentials and ammonium amalgams $\mathrm{R}_{4} \mathrm{~N}(\mathrm{Hg})_{\mathrm{n}}$ can be used in situ [1] as powerful reducing reagents. More recently, electroactive materials were shown to be produced electrochemically with some post-transition metals used as cathode materials with quaternary ammonium salts. Thus, metals like lead, tin, antimony, and bismuth yield to reductive reagents. Experimental conditions [2] permitted to produce materials where each ammonium is associated to a homopolyanion derived from the metal $\mathrm{M}$ (for example: $\left.\mathrm{R}_{4} \mathrm{~N}^{+}\left(\mathrm{M}_{5}\right)^{-}\right]$.

Additionally, the generation of homopolyanions $\mathrm{M}_{\mathrm{p}}{ }^{\mathrm{n}-}$ has been already reported [3]. The synthesis is based on the reduction of meta-metals salts by alkaline and alkaline-earth metals in liquid ammonia under specific conditions. The electrochemical method (based on the cathodic dissolution at room temperature of alloys used as cathode material) allowed the synthesis of a large palette of Zintl type complexes. Later on, the electrochemistry of heteropolyanions was developed especially those of weaker entropy $\left(\mathrm{Sn}_{9}{ }^{4-}\right.$ and $\left.\mathrm{Pb}_{9}{ }^{4-}\right)$.

Now, the intriguing question is: what cathodic reactivity if any, for platinum and palladium metals when used -under specific conditions- as cathodes materials? Below, are summarized with those metals the conditions that strongly lower the incidence of hydrogen evolution and permit to establish a specific reactivity and propose some patterns for modifying their surfaces.

\section{Basic experimental conditions for evidencing cathodic charge for platinum and palladium.}

Experiments relative to the present study relative to the "reduction" of platinum are principally achieved in N,N'-dimethylformamide (DMF). In any case, the essential condition is the use of a quasi dry solvent experimentally obtained by addition in situ of activated neutral alumina (by heating alumina at $340^{\circ} \mathrm{C}$ ) in the electrochemical cell [4-5]. Thus, the moisture of DMF was ascertained to contain less than $100 \mathrm{ppm}$ of water. A permanent storage of solvent over alumina gave best 
results. In most of the experiments, electrolyte concentration was $0.1 \mathrm{M}$. About salts, mostly alkaline iodides were used. Tetra-n-alkylammonium salts TAAX (puriss grade) were also privileged $\left(\mathrm{X}^{-}: \mathrm{BF}_{4}^{-}, \mathrm{ClO}_{4}^{-}, \mathrm{I}^{-}\right.$and $\left.\mathrm{PF}_{6}^{-}\right)$. All salts were dried by conventional methods before use. Electrolyte solutions were kept under alumina. The use of a glove box may bring facilities for further approaches.

For voltammetric investigations, standard three-electrode cells were used. Analytical studies were made on a smooth disk of Pt and Pd sealed in glass (area of 8 $\mathrm{x} 10^{-3} \mathrm{~cm}^{2}$ ). All potentials are here reported to aqueous $\mathrm{Ag} / \mathrm{AgCl}$. In practice using $\mathrm{Ag} / \mathrm{AgI} / 0.1 \mathrm{M} \mathrm{INBu}_{4}$ system (in DMF) may forbid any moisture diffusion.

Platinum electrodes were polished with silicon carbide paper of successively smaller size $(18$ to $5 \mu \mathrm{m})$, then by diamond powder (6 and $3 \mu \mathrm{m})$. Finally, electrodes were rinsed with ethanol and acetone and then dried with a hot air flow. Lastly, for macroelectrolysis investigations, $\mathrm{Pt}$ sheets $(99.99 \%$ purity, surface area of about 1 $\mathrm{cm}^{2}$, thickness $0.05 \mathrm{~mm}^{2}$ ) were used. They were employed only once for SEM investigations without further treatment.

Coulometric and EQCM experiments were carried out on thin metallic deposits prepared by very thin deposition of metals from solutions of $10 \mathrm{~g} \mathrm{l}^{-1} \mathrm{H}_{2} \mathrm{Pt} \mathrm{Cl}_{6}$ or $\mathrm{PdCl}_{2}$ in $0.1 \mathrm{M} \mathrm{HCl}$ onto polished gold disks $\left(2 \times 10^{-3} \mathrm{~cm}^{2}\right)$. The plating was achieved in a galvanostatic mode (current $10^{-2} \mathrm{~A} \mathrm{~cm}^{-2}$ ). Such platings could be used as well at smooth glassy carbon, $\mathrm{Pt}$, and $\mathrm{Pd}$. For analyses concerning stoichiometric determinations, all the experiments were performed with gold substrates (because very weakly reactive under strongly reducing conditions towards salts within potentials ranges here explored). That could be a gold microelectrode polished before each deposition, or (when EQCM experiments were carried out) a much larger electrode of commercial gold-coated quartz crystal.

Results with palladium (in charge in the quasi-absence of moisture, reduced in DMF different salts, $\mathrm{TAA}^{+} \mathrm{X}^{-}$or alkaline metal iodides) are roughly similar to those given above with Pt. Let use us note however that in some case, but not always, a stoichiometry of $\left\{\mathrm{Pd}_{4}{ }^{-}, \mathrm{M}^{+}, \mathrm{MA}\right\}$ could be found. Also, the ion insertion in metal led to extraordinary disturbances with formation of pores, channels and porosities at the nanometric scale. This would be applied as a material for use in heterogeneous catalysis.

\section{Reversible cathodic charge of platinum in super-dry conditions}


The first evidence of a reversible charge of platinum metal was obtained in a super dry solution (DMF + tetra-n-butylammonium iodide) [4]. The charge has been also achieved in the presence of alkaline metals cations always associated to iodide anion for a purpose of solubility. They display, at a Pt micro-cathode, a quasireversible peak [6]. The cathodic current is always associated to an anodic step peak. It could be checked that the anodic step corresponds to the oxidation of the cathode material formed if previously held at the level of the cathodic step. Charges observed with alkali metals ions appeared to strongly depend on the nature of the metal $\left(\mathrm{E}_{\mathrm{Li}+}\right.$ $\left.<<\mathrm{E}_{\mathrm{Na}^{+}} \approx-2 \mathrm{~V}\right)$. Coulometric studies based on the reduction of known deposits of Pt onto gold followed by the recovered electricity amounts permitted to fix the obtainment of a species $\mathrm{Pt}_{2}^{-}$possibly stabilized by a cation $[7,8]$. The use of a dynamic EQCM analysis (reversible increase of the mass upon reducing potential until a limit) permitted to show that all salts MX mentioned in this study produced a weakly conducting iono-metallic structure $\left\{\mathrm{Pt}_{2}{ }^{-} \mathrm{M}^{+}, \mathrm{MX}\right\}$ that efficiently covers the metal and quite certainly contributes to inhibit hydrogen evolution. The growing of the layer remains limited owing to its resistance estimated by means of electrochemical impedance spectroscopy [6]. Generally, platinum can be efficiently charged under conditions given in experimental §2 (DMF, moisture level $<100$ ppm, $\mathrm{E} \approx-2 \pm 0.2 \mathrm{~V}$ ). The reactivity of platinum in the presence of salts leads to surface changes and swellings that clearly depend on ion radii in presence $[6,8]$.

Results with palladium (also achieved in the quasi-absence of moisture, reduced in $\mathrm{DMF}$ different salts, $\mathrm{TAA}^{+} \mathrm{X}^{-}$or alkaline metal iodides) are roughly similar to those given above with Pt. Let use us note however that in some case, but not always, a stoichiometry of $\left\{\mathrm{Pd}_{4}{ }^{-} \mathrm{M}^{+}, \mathrm{MX}\right\}$ could be found. Also, the insertion of ions in the metal led to extraordinary disturbances with formation of pores, channels and porosities at the nano-metric scale (Figure 1, A, B, C, and D). This could be applied for generating materials for use in heterogeneous catalysis.

Electrolytic deposits of $\mathrm{Pt}$ onto platinum plates could be reduced as well. The charge of those thin layers (Figure 1, E and F) in the presence of $\mathrm{TAA}^{+}$ions produced spectacular coverages of spheres [9].

\section{Visualization of Pt swelling in real time thanks to EC-AFM.}

In order to observe surface changes in real time during redox processes, conducting surfaces made of large flats areas of platinum disposed on a surface of 
high porosity specific to the substrate $\mathrm{Pt} / \mathrm{MgO}$ were employed $[8,10]$. Potential monitoring permitted to show, in real time, the progressive swelling of Pt plates when potentials $<-2 \mathrm{~V}$ were reached. Getting back to potentials much less reducing allowed restoring the initial feature of surface and then checking the process reversibility.

\section{Morphology of modified surfaces upon ion insertion and then oxidation by dioxygen.}

As stressed above, Pt and Pd surface modification width depends on applied potentials and electricity amounts used in reduction processes. Thus, Pt reduction (Figure1 A) in DMF/CsI led to a surface pierced of several canals apparently oriented along the surface. With TBAI, grain boundaries are strongly dug: it is expected ions insertion follows preferably this route. Moreover, local enlargements (canals) could be due to the expulsion of bulky ions in the course of oxidation processes. Palladium surface is also enormously changed by insertion of ions (many evidences for an amorphous transformation of the interface, apparent porosity with many holes assigned to canal buildings).

\section{Platinum and palladium ionometallic forms as reducing reagents.}

It has been previously mentioned that air (dioxygen) can oxidize fast platinum and palladium intermediates. This evidence forbids any further structural and physical studies outside a glove box. A large number of $\pi$-acceptors were tested and reduced as the state of radical-anions or dianions (examples: chloranile, p-dinitrobenzene, 9-fluorenone reduced by $\mathrm{Pt}_{2} \mathrm{Cs}(\mathrm{CsI})$ ) [6]. When the standard potential of the $\pi$ acceptor is $<-1.5 \mathrm{~V}$, electron exchange starts being slow that permit to suppose the potential of the layer, on all its thickness, is roughly equal to $-1.2 \mathrm{~V}$ at least with $\mathrm{Cs}^{+}$ (Scheme 1, reaction 3). Evidently, reducing power of those layers is bound to the nature of the implied cations (larger efficiency with $\mathrm{Me}_{4} \mathrm{~N}^{+}$and $\mathrm{Li}^{+}$). Additionally, the nature of reduced organic species was checked by ESR (electrolytic pre-deposit on a thin Pt wire under oxygen free atmosphere). Employing ionic liquids as electrolyte in the reduction of Pt permitted the attachment of free aryl radicals ([11], reduction of aryldiazonium by the iono-metallic layer). 


\section{Embedding of acceptors in platinum. Towards new concepts for platinum electrodes.}

The most interesting (and fascinating) reaction of these iono-metallic layers obtained with Pt (and probably with Pd) lies in the occurrence of anion exchange (whatever their nature) inside the complex. This possibility was evidenced $[6,7]$ by adding $\pi$-acceptors in solution during or after the obtaining of Pt-complex layers (Figure 2 and Scheme 1, reactions 4 and 5). Paramagnetic materials can be obtained with chloranil or acenaphthenequinone (since not oxidized by air). Contrariwise, 1,4diacethylbenzene (Figure $2 \mathrm{~B}$ ), the produced complex is unstable at air leads to regenerate inside platinum the acceptor readily eliminated by acetone (work up) for leading to the $3 \mathrm{D}$ negative image of the iono-metallic layer. This evidence opens a new field about platinum electrodes: that of incorporating bulky (poorly soluble) bases such n-doped organic polymers, n-doped nano-particles of graphite and graphene. The insertion of carbon materials in platinum could then generate a new family of modified electrodes.

\section{Conclusion, perspectives}

The highly unexpected reactivity of platinum and palladium under electron transfer in super-dry electrolytes opens fantastic possibility in the field of conducting materials especially by the large possibility of insertion of organic and inorganic anions.

\section{References}

[1] L. Horner, H. Neumann,Chem. Ber., 98 (1965) 1715.

[2] E. Kariv-Miller, P. B. Lawin, J. Electroanal. Chem., 247 (1988) 345.

[3] E. J. Zintl, J. Goubeau, W. Z. Dullenkoff, Z. Phys. Chem., Abst. A 154 (1931) 1.

[4] J.Simonet, E. Labaume, J. Rault-Berthelot, Electrochem. Comm., 1 (1999) 252.

[5] P. Hapiot, J. Simonet, Electroanal. Chem., 23 (2010) 105.

[6] C. Cougnon, Ph.D. Thesis, Université de Rennes, 2002.

[7] C. Cougnon, J. Simonet, Electrochem. Comm., 3 (2001) 2509, Platinum Metals Rev., 46 (2002) 94 and unpublished results. 
[8] J. Ghilane, Ph.D . Thesis, Université de Rennes, 2005.

[9] J. Simonet, Electrochem. Comm., 402 (2003) 5, Platinum Metals Rev., 50 (2006) 180.

[10] J. Ghilane, M. Guilloux-Viry, C. Lagrost, P. Hapiot, J. Simonet, J. Phys. Chem., B 109 (2005) 14925, and J. Am. Chem. Soc., 129 (2007) 6654.

[11] J. Ghilane, J. C. Lacroix, J. Am. Chem. Soc, 135 (2013) 4722.

\section{Figure captions .}

\section{Figure 1}

Electrochemical treatment of platinum and palladium in super-dry DMF and MX salts [7].
A) Pt corrosion by CsI. E = -1.8 V. Amount of electricity: $27 \mathrm{C} . \mathrm{cm}^{-2}$.
B) Pt surface modified by NaI. $E=-1.6 \mathrm{~V}$. Electricity passed: $18 \mathrm{C} . \mathrm{cm}^{-2}$.
C) Pd polarized in LiI. $\mathrm{E}=-2.5 \mathrm{~V}$. Electricity: $15 \mathrm{C} . \mathrm{cm}^{-2}$.
D) Polarization of $\mathrm{Pd}$ in $\mathrm{Et}_{4} \mathrm{NBr} . \mathrm{E}=-2.2 \mathrm{~V}$. Electricity passed: $2.5 \mathrm{C} . \mathrm{cm}^{-2}$.
E) and F) Platinized platinum surfaces. Pt spheres generated in the presence of TBAI. Average Pt deposit: $0.22 \mathrm{mg} \cdot \mathrm{cm}^{-2}$. Oxidation by air and electrochemically $(\mathrm{E}=0 \mathrm{~V})$ respectively.

\section{Figure 2}

Electrolyses of $\pi$-acceptors at platinum in super dry conditions (here: DMF + CsI $0.1 \mathrm{M})$.

A) SEM images obtained with acenaphtenequinone $\left(10 \mathrm{mM} \mathrm{L}^{-1}\right)$. Applied potential: 2.0 V. Amount of electricity: $27 \mathrm{C} \mathrm{cm}^{-2}$. Response EDX: white zones: only Pt. Black zones are assigned to the embedding of the acceptor via the participation of the organic anion to the iono-metallic complex.

B) Similar experiment with 1,4-diacethylbenzene (reduction at $-2.0 \mathrm{~V}$, electricity amount: $22 \mathrm{C} \mathrm{cm}^{-2}$ ). Print of the organic acceptor implied in the iono-metallic complex then oxidized by air and dissolved by acetone during the work up $[6,7]$. 
Reduction of platinum (or palladium) in super dry media:

$$
2 \mathrm{Pt}+2 \mathrm{M}^{+} \mathrm{X}^{-}+\mathrm{e} \rightleftharpoons\left\{\mathrm{Pt}_{2}^{-} \mathrm{M}^{+}, \mathrm{MX}\right\}
$$

Electrochemical instability of the iono-metallic phase $(\mathrm{E}<-2.5 \mathrm{~V})$ :

$$
\left\{\mathrm{Pt}_{2}{ }^{-} \mathrm{NR}_{4}{ }^{+}, \mathrm{NR}_{4} \mathrm{X}\right\}+\mathrm{e} \longrightarrow \mathrm{Pt}+2 \mathrm{R}^{\circ}+2 \mathrm{NR} 3+\mathrm{X}^{-}
$$

Iono-metallic layer as reducing reagent through electron transfer:

$$
\left\{\mathrm{Pt}_{2}{ }^{-} \mathrm{M}^{+}, \mathrm{MX}\right\}+\mathbf{A} \stackrel{\mathrm{E}_{\mathrm{A}}^{\circ}>-1.5 \mathrm{~V}}{\longrightarrow} 2 \mathrm{Pt}+\left\{\mathbf{A}^{\cdot-} \mathbf{M}^{+}\right\}+\mathrm{MX}
$$

(3)

Insertion of electro-generated organic acceptors $(A)$ or bases $\left(B^{-}\right)$:

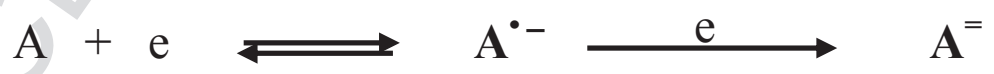

(4)

$$
\left\{\mathrm{Pt}_{2}{ }^{-} \mathrm{M}^{+}, \mathrm{MX}\right\}+\mathbf{A}^{\bullet-} \longrightarrow\left\{\mathbf{P t}_{\mathbf{2}}{ }^{-} \mathbf{M}^{+}, \mathbf{M}^{+} \mathbf{A}^{-}\right\}
$$

(5)

$$
\left\{\mathrm{Pt}_{2}{ }^{-} \mathrm{M}^{+}, \mathrm{MX}\right\}+\mathbf{B}^{-} \longrightarrow \quad\left\{\mathbf{P t}_{\mathbf{2}}{ }^{-} \mathbf{M}^{+}, \mathbf{M}^{+} \mathbf{B}^{-}\right\}
$$

(6) 


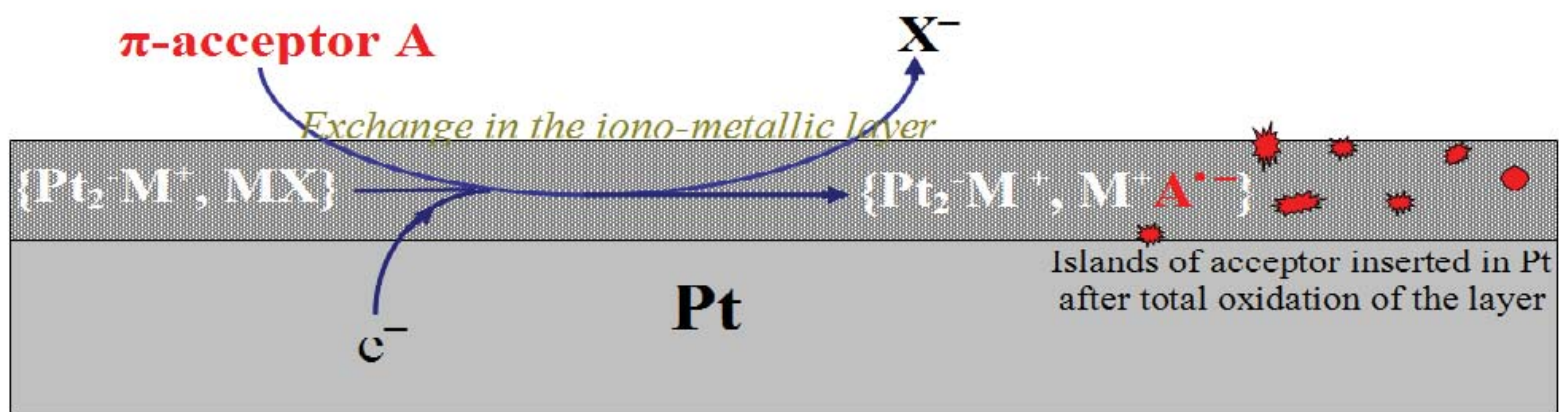

\section{Scheme 1}

Cathodic generation of iono-metallic layers from platinum in super-dry electrolytes. Some decomposition reactions. 



Figure 1 


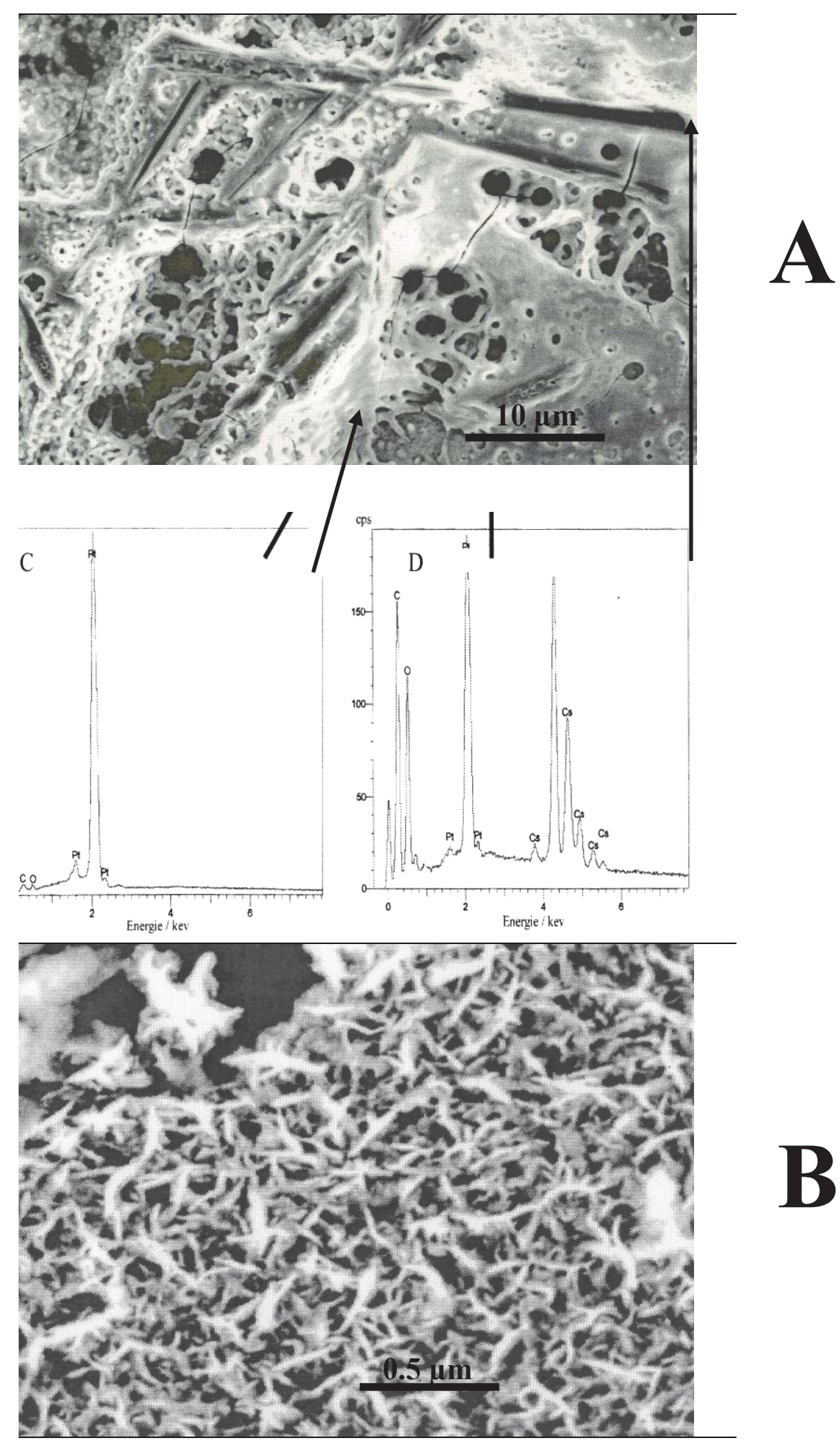

Figure 2 


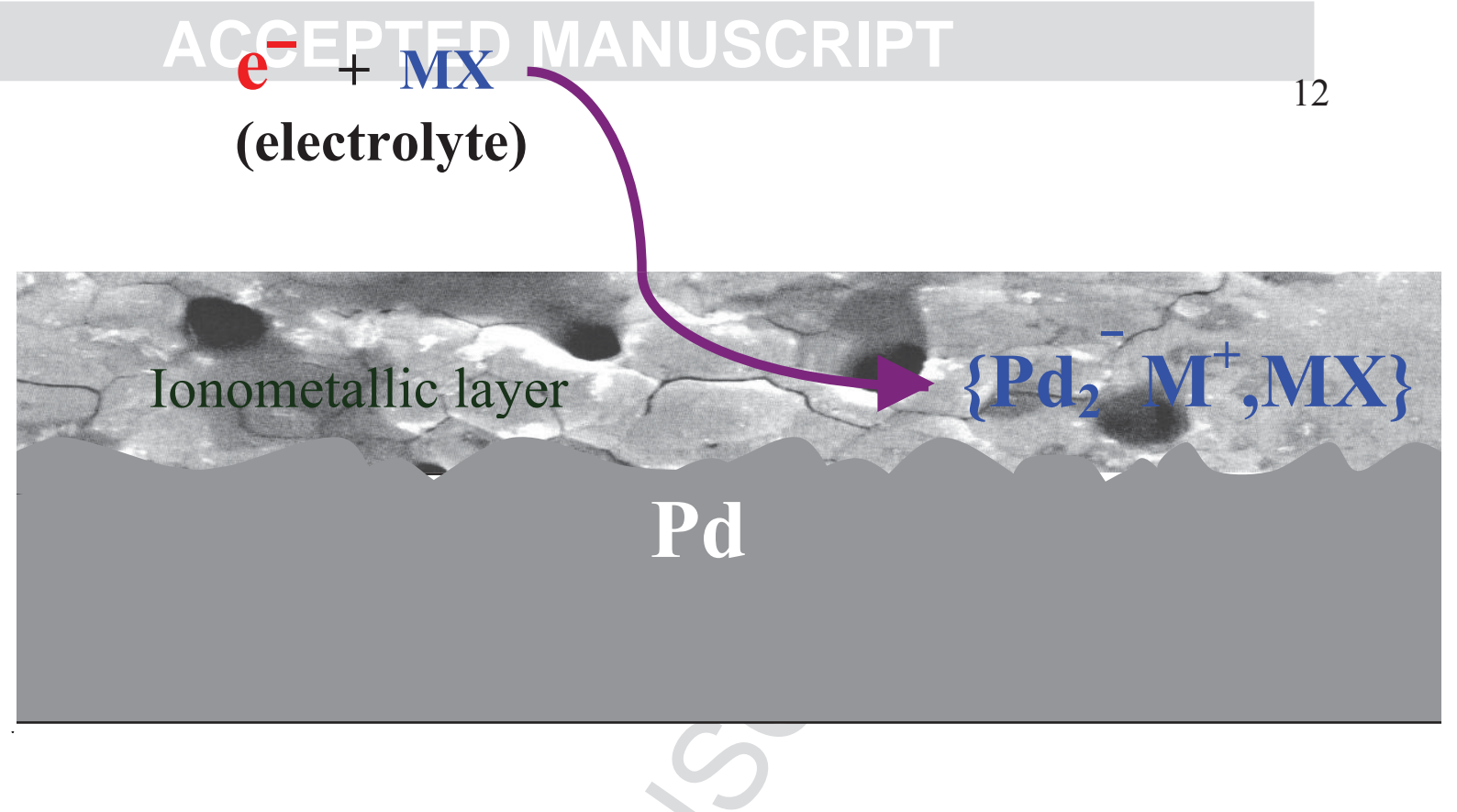

\section{Graphical abstract}




\section{Highlights}

Cathodic modifications of platinum and palladium in super-dry electrolytes $\mathrm{MX}>$ Formation of iono-metallic layers $\left\{\mathrm{Pt}_{2}{ }^{-} \mathrm{M}^{+}, \mathrm{MX}\right\}$ implying platinum or palladium $>$ Reactive surfaces as reducing reagents $>$ Insertion of organic $\pi$-acceptors in platinum $>$ A new process for modifying platinum interfaces.. 